\title{
An Analysis of the Effectiveness of the Teacher Qualification Training Program Before and During the COVID-19 Pandemic
}

\author{
Tae-Ho Choi ${ }^{1}$ \\ ${ }^{1}$ Educational Researcher, Center for In-service Education, Korea National University of \\ Education, Korea, thchoi@knue.ac.kr
}

\begin{abstract}
This study sought the groundbreaking change in the direction of teacher training at the present time towards the future-oriented educational paradigm change in preparation for the post-corona era through the basic researches on the training environment of the General Education and Training Institute. Through this, the future-oriented teacher training and the direction of research with characterization, specialization and differentiation of the teacher training were suggested. The current teacher training operation in the traning environment of the post-corona has many difficult limitations, thus, a more innovative teacher training environment should be constructed and the re-establishment of teacher training should be sought. In order to attain the purpose, researcher analyzed prior literatures related the teacher traing program based on the analysis results, extracted analysis tool and questionnaire, and then, conducted survey method. To evaluate the analysis of satisfaction and trend of the teacher qualification training program by General Education and Training Institute of the Korea National University of Education for the past four years, this study compared and analyzed the satifaction of teacher qualification training program of the pre-corona period from 2017 to 2019 and the teacher qualification training program in the corona era in 2020 including comparative analysis of the effectiveness of teacher training programs of the pre-corona and corona-era. The data were compared and analyzed to suggest the meaningful direction and operational plan for the innovative teacher training in preparation for the future and the post-corona period. Therefore, the results for this study are intended to help in proposing changes in the teacher qualification training program and also providing basic data for the educational study.
\end{abstract}

Keywords: Post Corona, Principal (Kindergarten) Qualification Training, Teacher Training Policy, Training Effectiveness, Teacher Training Policy Direction

\section{Introduction}

2020 is a year of crisis in education due to the COVID-19 pandemic. Since the outbreak of COVID19 in Wuhan, China in December 2019, it has spread rapidly around the world. In particular, the spread of COVID-19 is causing significant changes in the field of education[1]. According to the results of a recent survey of students on non-face-to-face classes at Seoul National University, the difficult factors in non-face-to-face classes were an increase in task and learning volume (23.1\%), instability in a network environment (18.5\%), and interaction difficulties with professors and colleagues (17.6\%) and among preferred medium for non-face-to-face teaching, students answered videos recorded by professors (34.1\%), ZOOM (28.5\%), and PPT recordings (20.2\%)[2]. In the situation, as a future-

Received: May 18, 2021; $1^{\text {st }}$ Review Result: July 02, 2021; $2^{\text {nd }}$ Review Result: August 22, 2021

Accepted: September 30, 2021 
oriented educational paradigm change in preparation for the future post-corona era is needed in this Corona 19 situation, this study sought a drastic change in the direction of teacher training and the basic studies of the training environment of the General Education and Training Institute. It is intended to present a future-oriented teacher training and research direction with specialization and differentiation of the teacher training through implementation. This started from the awareness that there is a limit to the current training operation in the post-corona training environment, and it is necessary to construct a more innovative training environment and seek re-establishment of teacher training.

To this end, this study set the folling research questions.

First, what is the status of teacher training at the Comprehensive Education and Training Institute before the outbreak of the COVID-19 in the past three years?

Second, what is the current status of teacher training at the General Education and Training Institute in the Corona situation (2020)?

Third, what should be the direction of teacher training in preparation for post-coronavirus and innovative teacher training operation?

In order to analyze the satisfaction and trend of the principal qualification training program operated by the General Education and Training Institute of Korea National University of Education, which is operating the qualification training for the principal in the context of this problem, the satisfaction of the teacher qualification training program operated for three years by the said institution before the corona and the effectiveness of the training program before and during the corona era (2020) were compared and evaluated. It is meaningful to explore the direction and operation plan for innovative teacher training in the future compared to the post-corona to analyze the satisfaction analysis of the teacher qualification training program operated by the Comprehensive Education and Training Institute of Korea National University of Education in charge of teacher qualification training for the past four years.

\section{Theoretical Considerations}

\subsection{Online Class}

Synchronous online courses can be considered as a new alternative to education delivery. COVID-19, which has ushered in the new normal era, is said to have pulled future education as well. In response to COVID-19, various new attempts were made in the education field, and the unfamiliar words brought by these attempts include 'online school opening', 'remote class', 'edutech', and 'real-time online class'. Among them, real-time online classes are one of the online class types that can be used to deliver nonface-to-face education in the COVID-19 situation suggested by the Ministry of Education. This realtime online class is one of the online class types, and refers to a class form in which the instructor and the learner connect to a video conference-based online class platform at different places but at the same time to perform learning activities in real time (S. K. Kang, 2020)[3]. By definition, real-time online classes are a type of online class where the "always" characteristic that has so far been representative of online classes has disappeared. Real-time online classes can provide a learning experience similar to face-to-face classes, and enable real-time interaction between learning participants (teacher-learner, learner-learner). In this regard, many educational institutions around the world have used the class type as an alternative education delivery method in the COVID-19 situation in the first half of 2020. To prove this, studies that explore the possibility of using real-time online classes and their actual use are being published. As a result of searching world-class research databases from Science Direct, Wiley Online Library, and Google Scholar, it was confirmed that more than 100 studies dealing with COVID-19 and real-time online classes were published between January and August 2020. In other words, COVID-19 has not only promoted the use of real-time online classes in the educational field, but also presents new research topics for researchers exploring education. 
The history and application of real-time online classes will be reviewed[4]. First of all, a concept that comes to mind naturally when thinking of online classes is a non-real-time online class based on recorded video that can be taken anytime, anywhere. Real-time online classes are an unfamiliar class type to Korean teachers, learners, and parents, within the basic perception of online classes. This study will explain the history and application of the corresponding class type, focusing on the US education field, which has been continuously conducting research and using the real-time online classes. The use of CCTV in the 1940s for educational purposes can be seen as the starting point of real-time online classes. From the 1980s, it can be seen that the use of real-time online classes enable real-time teachinglearning activities between instructors and learners.

From the 1980s to the late 1990s, studies were mainly conducted on the development of platforms that enable real-time online classes, and in the early 2000s, studies on the use of the corresponding class types based on the characteristics of real-time online classes were conducted. On the other hand, researchers and educators identified a number of constraints in the process of using real-time online classes, such as operational failures due to bandwidth limitations, insufficient functions of the platform, high costs for infrastructure construction, and difficulties in establishing class schedules. As a result, these factors decreased interest and utilization of real-time online classes[5].

In the 2010s, the use of real-time online classes increased again, mainly in the field of college education in the United States. Educators who used non-real-time online classes identified various limitations, such as the psychological isolation of online learners, the limitations of text-based communication, a decrease in the learner's sense of belonging, and the difficulty in implementing various teaching-learning strategies. In addition, the development of information and communication technology has resolved bandwidth limitations and difficulties in building platforms and infrastructure, which were previously a big limitation to the use of real-time online classes. Accordingly, educational institutions and professors began to use real-time online classes as an alternative to face-to-face classes and non-real-time online classes, and several studies explained the unique advantages of real-time online classes and promoted the use of the class type[6].

Minerva School is a representative educational institution that utilizes this education delivery method which can be called real-time online class or online video education in a different way. The Minerva School, a university-level educational institution that opened in 2014, utilizes a platform called the Active Learning Forum to utilize real-time online classes as its primary method of delivery. Even before the Minerva School, many US universities used real-time online classes while operating online degree programs. For example, in the case of the University of Tennessee, USA, a $100 \%$ online master's program in educational engineering has been running since 2013, focusing on real-time online classes. In the case of U.S. universities which have been using real-time online classes as a method of delivering education since before COVID-19, real-time online classes are an alternative to face-to-face classes in the COVID-19 situation based on the existing platform, either human or physical infrastructure[7].

In the context of the COVID-19 situation, real-time online classes have been a class delivery method used not only in education fields in Korea but also around the world. Researchers around the world have conducted various studies based on their experience of using real-time online classes in the COVID-19 situation. The studies that has explored the connection between COVID-19 and real-time online classes cover the following topics.

- Use cases of real-time online classes by area in the COVID-19 situation

- Strategies and resources to support instructors' use of real-time online classes

- Strengths, Weaknesses, and Utilization of Real-Time Online Classes as an Alternative to Face-toface Classes 
In the context of COVID-19, various studies on real-time online classes are expected to be published in the future as education sites around the world including Korea.

\subsection{Teacher Training}

\subsubsection{Directions of Pre-coronavirus Training Operations}

To strengthen its capacity to operate principal qualification training centered on core competencies to prepare for changes in future society according to changes in the social environment and educational needs of the Fourth Industrial Revolution, we tried to operate a future core competence-oriented principal qualification training program for fostering new principal leadership, the field-oriented approach to be implemented in the field of education new definitions of principal leadership capabilities, education autonomy and changes in government philosophy and education policies.

To develop and operate a participatory training program based on learners and field-oriented research, this study aims to foster consumer demand and field-based education leadership through the development and operation of participatory and field-specific training courses, to develop both theory and practice by developing and operating training programs centered on core competencies based on R\&D.

In order to reflect changes in education policy and to establish a plan through collecting opinions from trainees and organizational members, we tried to actively reflect major policy changes such as the focus direction of teacher training and the basic plan for annual principal qualification training.

The focus of the pre-corona principal qualification curriculum can be summarized as securing connection with major policies of the Education Ministry and municipal and provincial education offices, organizing a curriculum centered on the core competence of principal leadership based on social and environmental changes, expansion of customized curriculum based on consumers reflecting the demand of education sites, organization of participatory curriculum centered on trainees, and expanding the organization of timely autonomous subjects such as social enterprises, related subjects, and special lectures on humanities.

\subsubsection{Directions of After-coronavirus Training Operations}

The direction of the curriculum was set before the coronavirus situation worsened, and it was inevitable to spend much time organizing the curriculum by repeating the revision of the plan several times. Therefore, the direction of the curriculum in the corona era is as follows.

First, to secure connection with major education policies of the Education Ministry and the Metropolitan Office of Education, the direction of education for democratic citizens of schools and strengthening educational welfare was established as the direction of the curriculum. The goals include strengthening safety education (15 hours), enhancing the capacity for class innovation based on curriculum revision, preventing and responding to school violence, sexual violence, and cyber violence, education to prevent abuse of children and the disabled and strengthening the capacity for understanding the disabled, and students' suicide prevention and strengthening mental health management capabilities.

Second, the curriculum focused on the core competence of principal leadership according to changes in social environment including separation of curriculum by school level (kindergarten, elementary and secondary school) and enhancement of the principal's core capabilities, strengthening the reflective leadership capabilities based on redefining the principal's leadership, strengthening the capabilities to lead changes in school education according to changes in future society, developing the principal's leadership to create a school culture that supports future capabilities, and the capacities for class innovation and school space innovation according to the curriculum revision was set up.

Third includes the expanding customized curriculum centered on consumers reflecting the demand of 
the educational field, development of core capabilities for basic school organization management, such as curriculum, budget, facilities, personnel and service, promoting educational policies through the support of professional learning communities, development of communication skills with teachers, students, parents, and communities, improving the professionalism necessary for school operation, such as regulations on school operation and labor-management relations, and reinforcement of the ability of the principal related to education and welfare of students with learning disabilities.

Fourth includes the expansion of participatory curriculum centered on trainees, formulation of module subjects to enhance the principal's ability to innovate schools, strengthening the responsibility and ethics of the principal as a change manager of the educational field, education vision and value development including collective-mentoring training association for school operation plan, developing the principal's leadership to create a democratic school culture and communication skills and rational problem-solving skills.

Fifth includes expanding the programming of autonomous subjects in a timely manner for the education leader, organizing big history and optional humanities, strengthening emotional leadership capabilities such as sympathetic communication, spreading understanding of social values and social enterprises, development of core capabilities related to future environmental change and sustainable development education, an analysis of school operation cases and the operation of educational discussions in conjunction with the school operation plan.

The curriculum operation plans are Organization, review, and deliberation of curriculum through the curriculum operation review committee, composition of a pool of instructors and selection of excellent instructors through the instructor recommendation and selection review committee, reflect the characteristics of each school level by separately operating the qualification training curriculum for kindergarten principals and the qualification training curriculum for elementary and secondary school principals. Due to covid-19, various participatory training methods centered on trainees such as workshops, case presentations, fractional discussions, seminars, field visits, and experiences are applied, selection and application of teaching methods suitable for the characteristics and contents of the curriculum, connect theory and practice through the operation of curriculum modules that integrate theory and practice were conducted, discussions were revitalized, and the field of problem solving skills of school principals and creating creative education measures suitable for the educational environment through practical learning (replacement of overseas education experience) and fostering the qualities as leaders in the global era were improved.

\section{Research Methods and Procedures}

This study examined the current status of teacher training operation before the COVID-19 outbreak from 2017 to 2019, and the experiences of failures and successes in the education field on the onset of the outbreak in 2020. It sought the direction of teacher training in the future post-corona era and improve the operation after collecting basic data and analyzing the actual situation and cases. Furthermore, this study tried to examine the plans for operating teacher training at the Comprehensive Education and Training Institute in preparation for the post-corona. This aimed to enhance the completeness of the research by conducting qualitative research through individual interviews analysis.

\subsection{Research Subjects}

Research subjects are composed of kindergarten, elementary and secondary school principals, who engaged the Korea National University of Education Comprehensive Education and Training Institute. Also, the interview subjects were those who received qualification training for principal head of the General Education and Training Institute, and after various literature data within four years of data 
collection and analysis were compared and analyzed for each research content, changes and training plans were presented.

\subsection{Research Tools}

This study used the research tools - comprehensive evaluation survey questionnaire and interview questionnaire. The questionnaire was developed through these steps consisted of review of literature, revision through experts' reviews.

\subsection{Data Anaysis}

This study analyzed the mean and statisfaction by using the Excel Program 2018. The questionnaire items are composed of curriculum, educational assessment, experience training, training infrastructure and training effect.

\subsection{Research Procedure}

The detailed procedure of this study is as follows [Fig. 1].

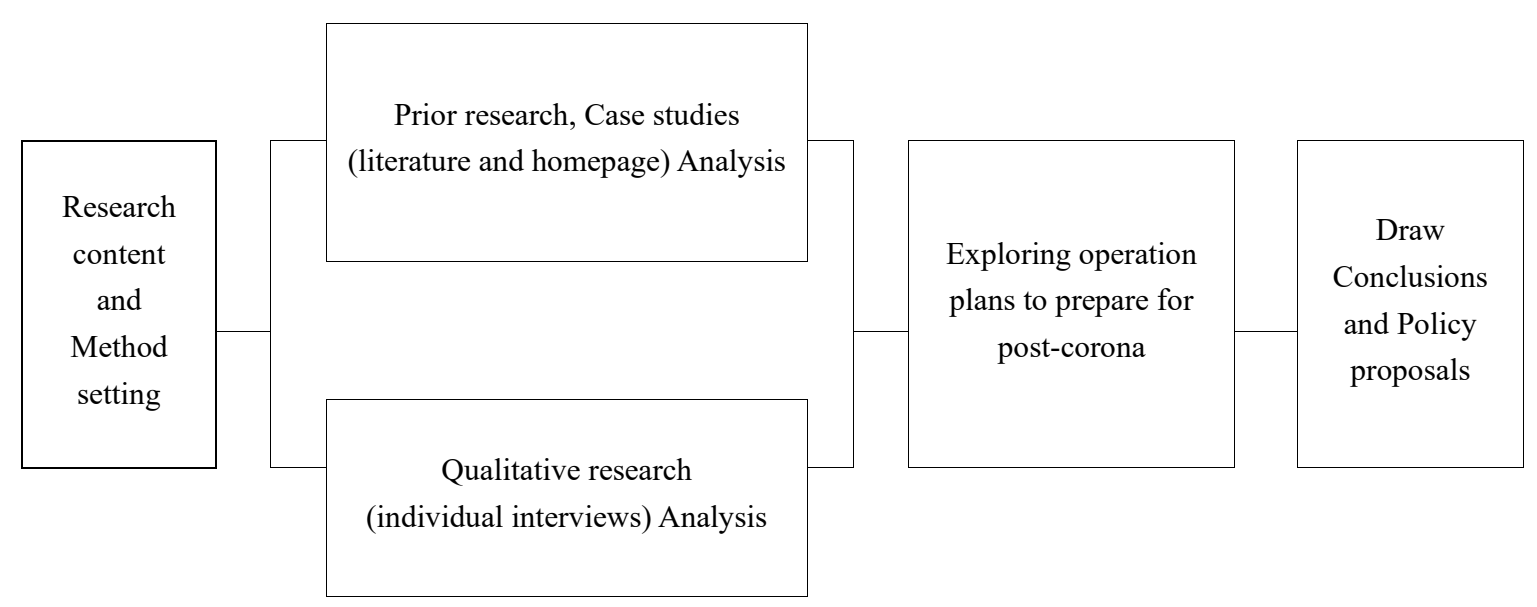

[Fig. 1] Research Process

\section{Research Results and Implications}

This is an exploratory study on the analysis of the effectiveness of the principal training program for future-oriented teacher training in preparation for post-corona era. In order to analyze this study, we tried to provide directions and implications for future teacher training through qualitative research methods such as case analysis, literature study, and individual interviews for trainees for four years.

\subsection{Pre-Coronavirus (2017-2019) Teacher Training Status and Actual Condition Analysis}

As the status of teacher training before Corona, we looked at the Ministry of Education's 'Promoting Directions for Teacher Training', training center development plan, standard curriculum organization standards, features and cases, and course organization. We analyzed the criteria for lecture evaluation, reflection of lecture evaluation results, effort and performance for instructor quality management, and 
the appropriateness of teaching methods[8].

The comprehensive evaluation questionnaire for training operation and instructor evaluation questionnaire for satisfaction with training program are as follows[9].

[Table 1] Questionnaire for Comprehensive Evaluation of Training Operation

\begin{tabular}{|c|c|c|c|c|c|c|c|}
\hline \multirow{2}{*}{ Sort } & \multirow{2}{*}{ Num } & \multirow{2}{*}{ Question (optional) } & \multicolumn{5}{|c|}{ Evaluation criterion } \\
\hline & & & $\begin{array}{l}\text { Very } \\
\text { likely }\end{array}$ & Likely & Normal & Unlikely & $\begin{array}{l}\text { Very } \\
\text { unlikely }\end{array}$ \\
\hline \multirow{2}{*}{ Curriculum } & 1 & Curriculum organization is appropriate & (5) & (4) & (3) & (2) & (1) \\
\hline & 2 & The method of education is effective & (5) & (4) & (3) & (2) & (1) \\
\hline \multirow{2}{*}{$\begin{array}{l}\text { Educational } \\
\text { assessment }\end{array}$} & 3 & The content and method of evaluation are reasonable & (5) & (4) & (3) & (2) & (1) \\
\hline & 4 & The assessment is fair and reliable & (5) & (4) & (3) & (2) & (1) \\
\hline \multirow{2}{*}{$\begin{array}{l}\text { Training } \\
\text { operation }\end{array}$} & 5 & Instructor selection was appropriate & (5) & (4) & (3) & (2) & (1) \\
\hline & 6 & The contents of the textbook were faithful & (5) & (4) & (3) & (2) & (1) \\
\hline \multirow{3}{*}{$\begin{array}{l}\text { Experience } \\
\text { training }\end{array}$} & 7 & Private experience training programs are effective & (5) & (4) & (3) & (2) & (1) \\
\hline & 8 & Mentoring training programs are effective & (5) & (4) & (3) & (2) & (1) \\
\hline & 9 & $\begin{array}{l}\text { Overseas education experience training programs are } \\
\text { effective }\end{array}$ & (5) & (4) & (3) & (2) & (1) \\
\hline \multirow{4}{*}{$\begin{array}{l}\text { Training } \\
\text { Infrastructure }\end{array}$} & 10 & satisfied with the training facility & (5) & (4) & (3) & (2) & (1) \\
\hline & 11 & satisfied with the educational materials & (5) & (4) & (3) & (2) & (1) \\
\hline & 12 & satisfied with the restaurant service & (5) & (4) & (3) & (2) & (1) \\
\hline & 13 & The staffs at the training center were kind & (5) & (4) & (3) & (2) & (1) \\
\hline \multirow{2}{*}{ Training effect } & 14 & This training will help the principal perform his duties & (5) & (4) & (3) & (2) & (1) \\
\hline & 15 & $\begin{array}{l}\text { The training program meets the purpose } \\
\text { of the principal's qualification training }\end{array}$ & (5) & (4) & (3) & (2) & (1) \\
\hline Sort & Num & \multicolumn{6}{|c|}{ Question (descriptive) } \\
\hline \multirow{3}{*}{ Curriculum } & 1 & \multicolumn{6}{|c|}{ What is the most useful subject? } \\
\hline & 2 & \multicolumn{6}{|c|}{ Which subject needs improvement? } \\
\hline & 3 & \multicolumn{6}{|c|}{ What subject do you want to open? } \\
\hline $\begin{array}{l}\text { comprehensive } \\
\text { opinion }\end{array}$ & 4 & \multicolumn{6}{|c|}{ Please write your thoughts on the training and other comments } \\
\hline
\end{tabular}


[Table 2] Instructor Evaluation Questionnaire

\begin{tabular}{|c|c|c|c|c|c|c|c|}
\hline \multirow{2}{*}{ Num } & \multirow{2}{*}{ category } & \multirow{2}{*}{ Questions (optional, descriptive) } & \multicolumn{5}{|c|}{ Evaluation criterion } \\
\hline & & & $\begin{array}{l}\text { Very } \\
\text { likely }\end{array}$ & Likely & Normal & Unlikely & $\begin{array}{l}\text { Very } \\
\text { unlikely }\end{array}$ \\
\hline 1 & $\begin{array}{l}\text { Subject } \\
\text { faithfulness }\end{array}$ & $\begin{array}{l}\text { Is the content of the lecture faithful to the topic and } \\
\text { useful? }\end{array}$ & (5) & (4) & (3) & (2) & (1) \\
\hline 2 & $\begin{array}{c}\text { Teaching and } \\
\text { learning methods }\end{array}$ & $\begin{array}{c}\text { Are lecture methods, materials, and time utilization } \\
\text { appropriate? }\end{array}$ & (5) & (4) & (3) & (2) & (1) \\
\hline 3 & $\begin{array}{l}\text { Plaintiff } \\
\text { suitability }\end{array}$ & $\begin{array}{l}\text { Is the lecture script faithful and consistent with the } \\
\text { lecture content? }\end{array}$ & (5) & (4) & (3) & (2) & (1) \\
\hline 4 & $\begin{array}{l}\text { Comprehensive } \\
\text { opinion }\end{array}$ & Please write down your other com & ats abou & the lectu & e in detail & & \\
\hline
\end{tabular}

In addition, through the analysis of satisfaction with the training program before Corona, it was found that the level of satisfaction was maintained at a fairly high level. This means that they are satisfied with the dynamic training program such as the formation of human networks in group training including overseas training. However, it is necessary to listen to the voices of many men in the training program, and the case of the training environment should be considered. Training operation centered on largescale lecture-style delivery needs to be supplemented, and it was found that trainees' improvement requirements for training facilities were found. Accordingly, the establishment of a training environment for online real-time training, such as the establishment of a studio, was an inevitable prerequisite.

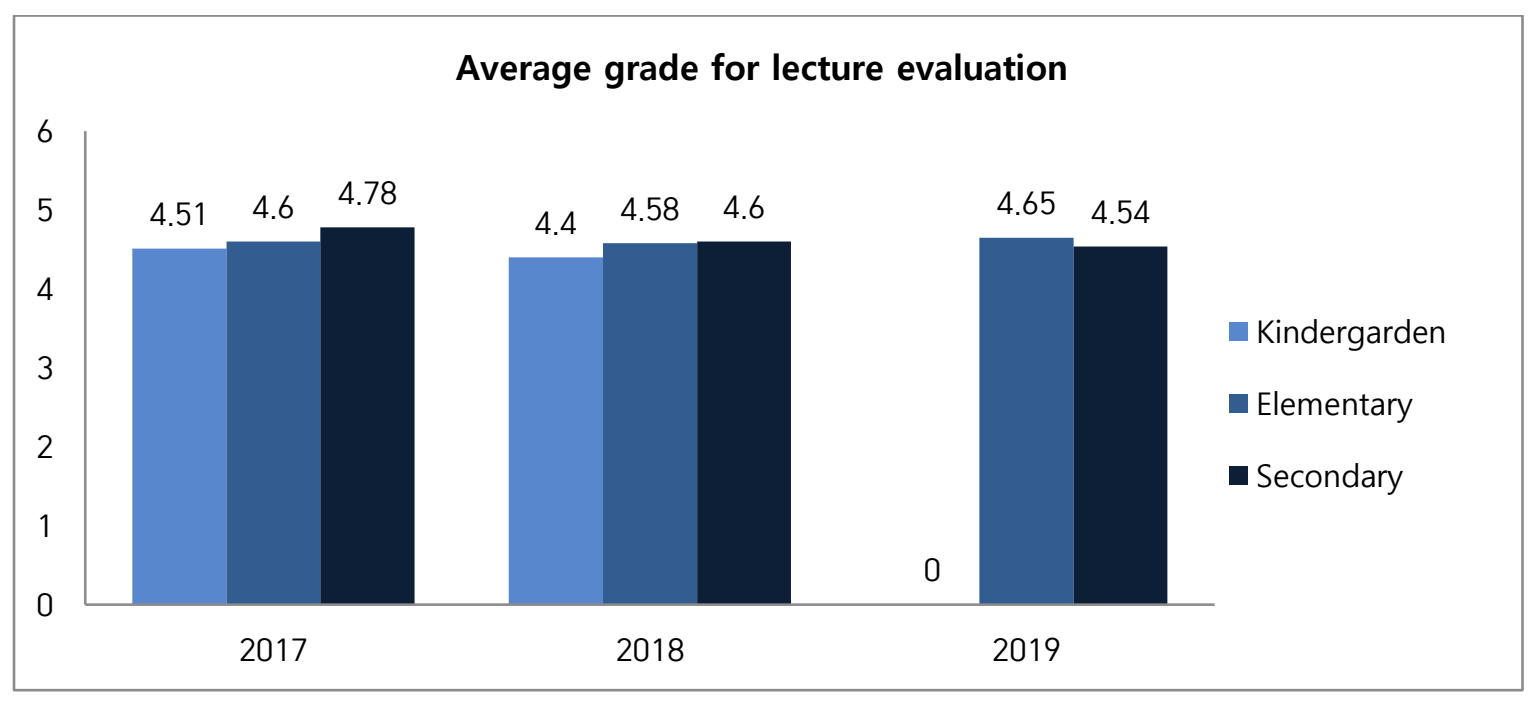

[Fig. 2] Distribution of Average Score for Course Evaluation

Satisfaction with the overall operation of the training was quite high, but it seems to be a natural result that can be felt in training before the Corona era. Satisfaction with overseas training and mentoring 
training was very high, which proves that it was a program of rights that principal trainees should naturally enjoy. As we enter the Corona era, in a training environment where we do not enjoy the rights we are entitled to, the operation of training inevitably brings its own difficulties.

[Table 3] Satisfaction with Pre-corona Training

(Unit: people, points)

\begin{tabular}{|c|c|c|c|c|c|c|}
\hline Year & Classification & $\begin{array}{l}\text { Number of } \\
\text { trainees }\end{array}$ & $\begin{array}{l}\text { Number of } \\
\text { respondents }\end{array}$ & $\begin{array}{l}\text { Satisfaction } \\
\text { Average score }\end{array}$ & $\begin{array}{c}\text { Average score by } \\
\text { Year }\end{array}$ & $\begin{array}{c}\text { All } \\
\text { Average score }\end{array}$ \\
\hline \multirow{3}{*}{2017} & $\begin{array}{l}\text { Elementary school } \\
\text { Principal }\end{array}$ & 220 & 205 & 95.0 & \multirow{3}{*}{94.2} & \multirow{8}{*}{93.6} \\
\hline & $\begin{array}{l}\text { Secondary school } \\
\text { Principal }\end{array}$ & 241 & 228 & 96.2 & & \\
\hline & Kindergarten Director & 268 & 243 & 91.5 & & \\
\hline \multirow{3}{*}{2018} & $\begin{array}{l}\text { Elementary school } \\
\text { Principal }\end{array}$ & 272 & 261 & 92.9 & \multirow{3}{*}{91.8} & \\
\hline & $\begin{array}{l}\text { Secondary school } \\
\text { Principal }\end{array}$ & 293 & 282 & 94.4 & & \\
\hline & Kindergarten Director & 230 & 213 & 88.1 & & \\
\hline \multirow{2}{*}{2019} & $\begin{array}{l}\text { Elementary school } \\
\text { Principal }\end{array}$ & 248 & 235 & 96.4 & \multirow{2}{*}{94.8} & \\
\hline & $\begin{array}{l}\text { Secondary school } \\
\text { Principal }\end{array}$ & 317 & 290 & 93.1 & & \\
\hline
\end{tabular}

In the search for improvement measures to prepare for the post-corona, it was suggested that the essential direction of teacher training should be established by planning and operating a training program by making use of the strengths and supplementing the weaknesses as much as possible, rather than settling on the high satisfaction levels before the corona.

The Korea National University of Education Comprehensive Education and Training Institute operates national-level teacher training and performs a role comparable to that of an institution directly under the national administration (the Ministry of Education). Nevertheless, it is facing difficulties in the Corona 19 situation, such as a new challenge phase, being put to the test for the underdeveloped teacher training environment and Corona response ability, and it is reaching the present without maintaining the high quality of the training. In preparation for the post-coronavirus, we need to think about establishing a true teacher training direction and enhancing our status as an institution that operates teacher qualification training. Above all, it will remind us that we need to show a model for teacher training and strengthen the sense of accountability and publicity that we need to lead.

\subsection{Analysis of the Current Status of Teacher Training in the Era of Corona (2020)}

First of all, looking at the analysis and implications of 'training operation evaluation results', the contents of the analysis of the evaluation results for each field of evaluation for the 2020 principal (principal) qualification training operation are as follows. 
[Table 4] 2020 Principal(kindergarten) Qualification Training Operation Evaluation Results by Area

\begin{tabular}{|c|c|c|c|c|c|c|c|c|}
\hline \multicolumn{2}{|c|}{$\begin{array}{l}\text { School Level } \\
\text { / Degree }\end{array}$} & Curriculum & \multirow{2}{*}{$\begin{array}{c}\begin{array}{c}\text { Educational } \\
\text { Evaluation }\end{array} \\
3.90\end{array}$} & \multirow{2}{*}{$\begin{array}{c}\text { Education } \\
\text { Operation } \\
4.00\end{array}$} & \multirow{2}{*}{$\begin{array}{c}\begin{array}{c}\text { Experience } \\
\text { Training }\end{array} \\
4.20\end{array}$} & \multirow{2}{*}{$\begin{array}{c}\begin{array}{c}\text { Training } \\
\text { Infrastructure }\end{array} \\
4.10\end{array}$} & \multirow{2}{*}{$\begin{array}{c}\begin{array}{c}\text { Training } \\
\text { Effect }\end{array} \\
4.15\end{array}$} & \multirow{2}{*}{$\begin{array}{c}\text { Overall } \\
\text { Rating } \\
4.05\end{array}$} \\
\hline & 1 & 3.95 & & & & & & \\
\hline \multirow[t]{2}{*}{ Elementary } & 3 & 4.15 & 4.20 & 4.35 & 4.45 & 4.05 & 4.30 & 4.25 \\
\hline & 4 & 4.50 & 4.55 & 4.60 & 4.15 & 4.20 & 4.55 & 4.43 \\
\hline \multicolumn{2}{|c|}{ Small Average } & 4.20 & 4.22 & 4.32 & 4.27 & 4.12 & 4.33 & 4.24 \\
\hline \multirow{4}{*}{ Secondary } & 1 & 4.20 & 4.15 & 4.25 & 4.30 & 4.00 & 4.30 & 4.20 \\
\hline & 2 & 4.30 & 4.15 & 4.30 & 4.35 & 4.15 & 4.35 & 4.27 \\
\hline & 3 & 4.55 & 4.45 & 4.60 & 4.60 & 4.45 & 4.65 & 4.55 \\
\hline & 4 & 4.55 & 4.45 & 4.60 & 4.10 & 4.25 & 4.55 & 4.42 \\
\hline \multicolumn{2}{|c|}{ Small Average } & 4.40 & 4.30 & 4.44 & 4.34 & 4.21 & 4.46 & 4.36 \\
\hline \multicolumn{2}{|c|}{ Kindergarten } & 4.40 & 4.25 & 4.40 & 4.25 & 4.15 & 4.45 & 4.32 \\
\hline \multicolumn{2}{|c|}{ Small Average } & 4.40 & 4.25 & 4.40 & 4.25 & 4.15 & 4.45 & 4.32 \\
\hline \multicolumn{2}{|c|}{ Ttal Average } & 4.33 & 4.26 & 4.39 & 4.29 & 4.16 & 4.41 & 4.31 \\
\hline
\end{tabular}

First, overall, in all areas, the satisfaction of secondary school principals (comprehensive score 4.36) was the highest, followed by kindergarten director (comprehensive score 4.32), and elementary school principals (comprehensive score 4.24). The average score of all areas for the principal was 4.31.

Second, the satisfaction level of elementary school principals generally increased as the number of rounds passed, and the case of the third grade was the highest for middle school principals. It can be seen that the level of satisfaction of the kindergarten director was considerably lower than that of the previous year because the kindergarten director operated only once a year.

Third, the average grades of elementary school principals in the training operation evaluation of the 2020 principal qualification training were 4.24 points, 4.36 points for secondary school principals, and 4.32 points for kindergarten directors, showing an average satisfaction rate of $86.2 \%$.

The highest score in average satisfaction by domain was 4.70, which was the mentoring training effect at the kindergarten director, and the lowest satisfaction was in the training infrastructure domain of secondary school principals and kindergarten directors at 3.70 , and 1.00 points $(20.0 \%)$ between the highest and lowest satisfaction.

Next, based on the analysis of 'instructor evaluation results' and implications, the average instructor evaluation score for the 2020 principal qualification training in the Corona 19 situation was 4.70 points for elementary school principals, 4.73 points for middle school principals, and 4.70 points for kindergarten directors. This is considered to be a reflection of dissatisfaction with other training programs such as overseas training. 


\subsection{Results of Qualitative Research (Analysis of individual interviews results)}

As a result of the individual interviews, we were able to recognize that there are significant complaints about the overall operation of the principal qualification training in response to COVID-19. There has been a flood of requests to allow training to be resumed while the COVID-19 situation has calmed down. There are parts that fully understand and sympathize with the situation of the training center in the era of Corona 19, but it is expected that the training center will have concerns about finding a better training direction.

In particular, implementation learning, which failed to conduct overseas training and took on administrative-oriented appearance, had a good introduction and purpose, but it became an element of dissatisfaction as it produced various difficult situations such as budget execution in terms of implementation. Although there were no major complaints about the curriculum and training schedule, a sharp critical opinion on the inadequacy of the discussion and evaluation of the assignments was expressed, and the strong need for improving the teacher training program for the future postcoronavirus of the Comprehensive Education and Training Institute was suggested.

The subjects of the online survey showed that the Korea National University of Education and Training Institute had more than 30 years of experience in operating the qualification training for principal qualifications and had a very good experience, but in the era of COVID-19 in 2020, many disappointments and dissatisfactions were expressed by the trainees.

Due to the covid-19 overseas training was not carried out and all the training programs were conducted online, thus, the strength of collective training of organizing a human network between trainees is difficult. As a result, it was considered to be a source of administrative and financial complaints.

It was suggested that there is a need to think about the future direction of teacher training in preparation for the post-corona era, and in particular, strong concerns and a will to practice in relation to efficiency, simplification, and evaluation of training administration are more realistic. This will be an important starting point in the field of 'teacher training' in the future of Korean education, and it is thought to be a reminder that the new paradigm of 'teacher training' is the mission of the times[10].

In other words, by valuing the experience of the 2020 corona era, the study was able to get a result that we should break away from the current teacher training operation system in preparation for the postcoronavirus, establish a new innovative teacher training ecosystem, and strongly promote changes in teacher training and efforts of the Comprehensive Education and Training Institute to revitalize the professionalism of teachers[11].

\section{Improvement Plan (Policy Suggestion)}

The suggestions for improvement based on the research results are as follows.

First, it is necessary to think about how to respond within the scope of the training center's discretion through the revision of related laws and regulations necessary to prepare for the post-coronavirus. The current laws and regulations related to teacher training are not in place to prepare for situations in which training is difficult to be conducted smoothly.

Second, it is necessary to restructure the human resources system for the post-corona era through reorganization of the training institute. Furthermore, it is necessary to reorganize the training environment, such as building a studio.

Third, it is necessary to reflect on the essential questions of teacher training to innovate anew by using the valuable experience gained from forced experience as an opportunity. It is necessary to prepare for the post-corona era by reestablishing the direction of teacher training and organizing innovative programs for teacher training.

Fourth, the negative opinions of trainees about non-face-to-face online real-time classes are not 
formidable. It is necessary to prepare alternatives to solve not only technical problems such as difficulties in access and interruption of training caused by system problems, but also the lack of preparation for non-face-to-face classes, inexperienced operation, and lack of communication.

Fifth, a new training model should be proposed by taking a revolutionary approach to curriculum and operation, schedule improvement, and evaluation system improvement[12].

\section{References}

[1] Abdullah M. Al-Ansi, Implementation of ICT at University Level during Covid-19 Pandemic: An Evidence from Yemen, Asia-Pacific Journal of Educational Management Research, (2021), Vol.6, No.1, pp.35-52, DOI:10.21742/ajemr.2021.6.1.04

[2] H. R. Min, Seoul National University's non-face-to-face training implementation status and results, Presentation materials for the 7th Gwanak Education Forum, (2020)

[3] S. K. Kang, Diagnosis and tasks of the national-level distance education system responding to Corona 19, The 14th Cheongram Education Forum Materials Collection, (2020)

[4] J. W. Do, Understanding Instructor's Synchronous Online Course Design Activity, University of Tennessee, Knoxville, Doctoral Dissertation, (2018)

[5] Ju-kyoung Kim, A Study of the Structural Relationships among K-MOOC Educational Suitability, Teaching Presence, Social Presence, and Learning Outcomes, Asia-Pacific Journal of Educational Management Research, (2021), Vol.6, No.1, pp.63-72, DOI:10.21742/AJEMR.2021.6.1.06

[6] Thanikachalam Vedhathiri, "Corruptocracy" Harms High Performing Faculty in Engineering Education, Asia-Pacific Journal of Educational Management Research, (2021), Vol.6, No.1, pp.73-100, DOI:10.21742/AJEMR.2021.6.1.07

[7] J. W. Do, An Investigation of Design Constraints in the Process of Converting Face-to-face course into Online Course, Journal of Education \& Culture, (2020), Vol.26, No.2, pp.153-173, DOI : 10.24159/joec.2020.26.2.153

[8] Focus on the direction of faculty training in 2021, Ministry of Education (Teacher Welfare Training Division), (2020)

[9] http://tcie.knue.ac.kr/index.do, May 2 (2021)

[10] http://www.moe.go.kr/, Mar 22 (2021)

[11] J. H. Lim, K. H. Ryu, B. C. Kim, An Exploratory Study on the Direction of Education and Teacher Competencies in the 4th Industrial Revolution, THE JOURNAL OF KOREAN EDUCATION, (2017), Vol.44, No.2, pp.5-32, DOI : 10.22804/jke.2017.44.2.001

[12] K. Y. Kim, The microscopic research of the extended implementation of the principal appointment system and policy conflicts, The Politics of Education, (2010), Vol.17, No.3, pp.7-33, UCI : G704-SER000009222.2010.17.3.001 